\title{
Polímeros reciclados para contato com alimentos
}

\author{
Sandra A. Cruz, Éder C. Oliveira, Fernando C. S. de Oliveira, Pâmela S. Garcia, Manuela L. Q. A. Kaneko \\ Centro de Engenharia, Modelagem e Ciências Sociais Aplicadas, UFABC
}

Resumo: Os resíduos sólidos urbanos (RSUs) são atualmente um dos maiores problemas ambientais, por serem gerados em grande quantidade e ocuparem extensos espaços por um longo período, resultando na diminuição do tempo de vida útil dos aterros sanitários. Os polímeros constituem um grande percentual da composição do RSUs, sendo que as embalagens plásticas contribuem com maior volume e massa. Apesar da reciclagem de polímeros estarem se consolidando no Brasil, graças ao seu mercado ascendente e promissor, existem ainda restrições quanto a sua utilização em contato com alimentos devido aos eventuais processos de migração de contaminantes que podem ocorrer da resina reciclada para o alimento. Por outro lado, dados recentes do setor indicam que a maior parte do consumo de resina virgem é destinada, justamente, para o mercado de embalagens alimentícias. Assim, o desenvolvimento e o gerenciamento de tecnologias que possibilitem o retorno destes materiais a sua aplicação original é de grande importância para sociedade contemporânea. Em um panorama geral, este trabalho aborda as exigências e limitações do uso de polímeros reciclados para contato com alimentos.

Palavras-chave: Reciclagem, polímero, embalagem para alimento, resíduos pós-consumo.

\section{Recycled Polymers for Food Contact}

Abstract: Municipal solid waste has recently become one of the severest environmental problems. This is because it is generated on a large scale and occupies large spaces for long periods resulting in a decrease in the useful life of landfills. Polymers comprise a large percentage of municipal solid waste and polymer packaging is responsible for the large mass and volume amount. Despite the consolidation of polymer recycling in Brazil, due to the promising and growing market, there are still restrictions concerning to its application for food contact due to eventual migration process that might occur from the recycled resin into the food. On the other hand, recent data of the sector indicates that food packaging market is responsible for the highest consumption of the produced amount of virgin polymers. Therefore the development and management of technologies that facilitate the returning of these materials to their original purpose are urgently needed. In general, this article focuses on the needs and limitations of the return process of the recycled polymer to the food contact package.

Keywords: Recycling, polymer, packaging for food, municipal solid waste.

\section{Introdução}

Apesar dos polímeros conquistarem, aos poucos, seu espaço como material de grande importância para a sociedade atual, seu descarte é ainda um problema mundial, e principalmente para o Brasil. Sua baixíssima degradabilidade e o seu elevado volume fazem com que seus rejeitos ocupem uma grande área por longos períodos, prejudicando a vida útil dos aterros sanitários ${ }^{[1]}$.

No Brasil, a falta de gerenciamento dos resíduos sólidos urbanos (RSU) resulta em descarte inadequado, e pode contribuir para entupimentos de redes de esgoto, propiciar condições de proliferação de vetores, gerando graves problemas ambientais. Segundo dados, de 2008, do Instituto Brasileiro de Geografia e Estatística - IBGE $^{[2]}$ são coletados, anualmente, cerca de 67 milhões de $\mathrm{t}$ desses resíduos. Porém, dados de $2009^{[3]}$ indicam que 7 milhões de t de RSUs deixaram de ser coletados, o que pode ter resultado em uma destinação inadequada. Este fato aponta que o país ainda é deficiente na implementação de ações para minimização da geração e destinação correta de resíduos.

Este aumento se justifica, principalmente, devido ao crescimento acentuado dos bens de consumo, ao aumento da produção industrial e ao crescimento gradativo e desordenado da população.

Neste contexto, caracterizar a composição dos RSUs é importante no sentido de se obter subsídios e informações adequadas para uma correta avaliação do planejamento e verificação da eficiência dos sistemas de coleta e disposição final. Além disso, pode ser uma importante ferramenta para a indústria da reciclagem de materiais, na medida em que direciona a produção do reciclador para determinada matéria-prima, indicando o produto mais adequado, qual matéria pode ser obtida mais facilmente e em qual época do ano, etc ${ }^{[4-6]}$.

Normalmente, a composição do RSU é subdividida em cinco tipos de resíduos: matéria orgânica, vidros, metais, plásticos e papéis ${ }^{[5]}$. Segundo um estudo realizado pelo Compromisso Empresarial para a Reciclagem (CEMPRE) sobre a composição média da coleta seletiva realizada em 2008 ${ }^{[7]}$, os resíduos plásticos, no Brasil, estão em torno de $22 \%$ em massa, como pode ser observado na Figura 1.

Apesar desses dados, ainda há uma carência na literatura relacionada à composição dos RSUs no Brasil. Os trabalhos encontrados referentes aos resíduos, muitas vezes, utilizam metodologias diferentes para a sua quantificação, de acordo com a gestão e o gerenciamento dos mesmos, o que dificulta análises reais da composição dos resíduos sólidos existentes no país. Pinheiro e Girard estudaram a composição gravimétrica dos RSD (resíduos sólidos domiciliares) produzidos no município de Belém (PA) no ano de 2006 ${ }^{[8]}$. Foi encontrada a seguinte composição: plástico (14,98\%), papelão (17,06\%), metal $(2,64 \%)$, vidro $(1,52 \%)$, material orgânico compostável $(45,89 \%)$ e outros $(17,91 \%)$. Em âmbito internacional também foram encontrados dados, do ano de 2006, da composição percentual do resíduo sólido nas subdivisões de cada continente ${ }^{[9]}$. Para a América do Sul obteve-se a seguinte composição: restos de alimento (44,9\%), papel/cartão $(17,1 \%)$, madeira $(4,7 \%)$, têxtil $(2,6 \%)$, borracha/ couro $(0,7 \%)$, plásticos $(10,8 \%)$, metais $(2,9 \%)$, vidro $(3,3 \%)$ e

Autor para correspondência: Sandra A. Cruz, Centro de Engenharia, Modelagem e Ciências Sociais Aplicadas, Universidade Federal do ABC

Rua Santa Adélia, 166, Bangu, CEP 09090-400, Santo Andre, SP, Brasil, e-mail: sandra.cruz@ufabc.edu.br 


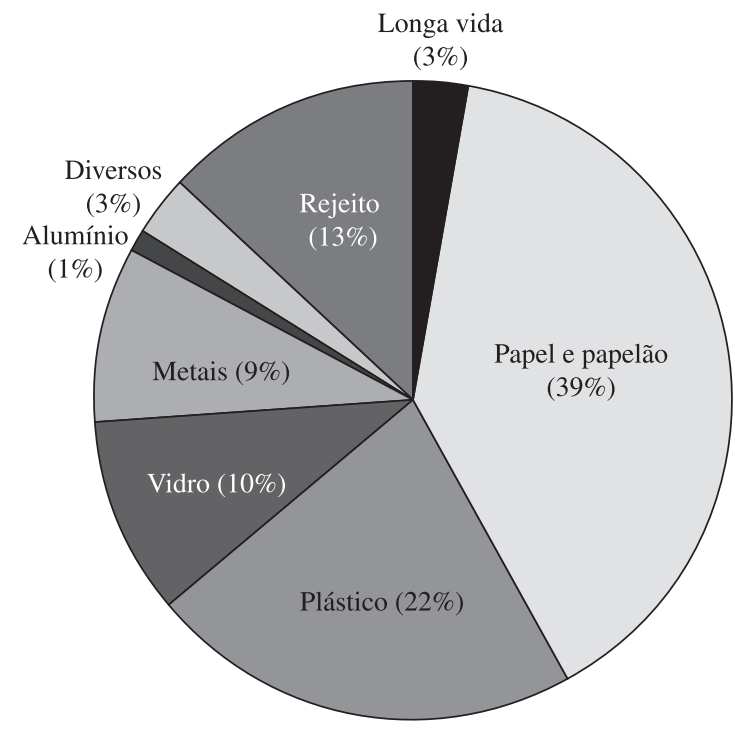

Figura 1. Composição mássica dos resíduos sólidos urbanos em sistemas de coleta seletiva no Brasil em 2008 ${ }^{[7]}$

outros (13,0\%). Já na América do Norte a porcentagem dos resíduos sólidos foi de: restos de alimento $(33,9 \%)$, papel/cartão $(23,2 \%)$, madeira (6,2\%), têxtil (3,9\%), borracha/couro $(1,4 \%)$, plásticos $(8,5 \%)$, metais $(4,6 \%)$, vidro $(6,5 \%)$ e outros $(9,8 \%)$. Em todas as pesquisas apontadas anteriormente nota-se que, dentre os materiais recicláveis, os resíduos plásticos apresentaram um papel de destaque, devido a sua alta porcentagem.

Dentre as indústrias que mais contribuem para a geração de resíduo plástico está a de embalagens ${ }^{[10]}$, situando-se entre as de maior crescimento nos últimos anos. $\mathrm{O}$ desenvolvimento de novas técnicas e processos de produção aliado ao baixo preço das resinas termoplásticas, tornaram as embalagens plásticas um componente essencial para a venda de produtos.

Dados recentes do setor indicam que aproximadamente $35 \%$ do consumo da resina virgem são destinadas, justamente, para embalagens alimentícias ${ }^{[11]}$. Portanto, seria fundamental que houvesse um retorno destes materiais a sua aplicação original, garantindo um mercado ascendente, fechando o ciclo de vida útil dessas embalagens e promovendo agregação de valor, pois a resina destinada para o segmento de alimentos possui maior valor de mercado. No entanto, para o seu retorno, torna-se imprescindível o desenvolvimento de tecnologias e pesquisas relacionadas à reciclagem de modo a viabilizar a sua utilização.

\section{Processos de Reciclagem}

No Brasil é comum a aplicação de conceitos definidos pela Sociedade Americana de Ensaios de Materiais - ASTM ${ }^{[12]}$. Este órgão descreve os diversos tipos de processos para reciclagem como: primária, secundária, terciária e quaternária. A reciclagem primária, também conhecida como reciclagem mecânica, consiste na recuperação de aparas, rebarbas ou peças defeituosas produzidas no processo de transformação ${ }^{[12,13]}$. Um outro tipo de reciclagem mecânica, também conhecida como reciclagem secundária, consiste na recuperação de material proveniente de resíduos pós-consumo, que através de processos operacionais tais como lavagem, moagem e secagem são novamente extrudados e peletizados para geração dos novos produtos. A reciclagem terciária é uma reciclagem química, que ocorre através da quebra das cadeias poliméricas, que por meio de reações de despolimerização produz monômeros, que poderão ser novamente polimerizados. Neste processo a geração de subprodutos, os quais são destinados para outros setores industriais, também é comum. Por fim, tem-se a reciclagem quaternária, ou seja, a reciclagem energética, que se baseia na recuperação de energia a partir da incineração de resíduos plásticos ${ }^{[12,13]}$.

A maior parte das empresas brasileiras utiliza em seu processo a reciclagem mecânica, devido à fatores que podem ser descritos como: custo de mão-de-obra, baixo investimento para instalação da planta de reciclagem, disponibilidade de matéria-prima, mercado crescente para a venda de polímeros reciclados, dentre outros ${ }^{[14]}$.

No Brasil, a reciclagem mecânica vem crescendo em volume e aumentando a diversidade dos produtos. Isto se deve, pelo menos em parte, ao aumento do preço da resina virgem e a qualidade da resina reciclada decorrente do aumento no grau de profissionalismo do setor. Além disso, de uma maneira geral, diversos estudos têm sido realizados no sentido de aprimorar o desenvolvimento de processos que proporcionem à resina reciclada propriedades similares as da resina virgem, o que resulta, invariavelmente, em avanços científicos para a área de reciclagem mecânica ${ }^{[15-20]}$. Entretanto, a aplicação dos polímeros reciclados para a confecção de embalagens para alimentos ainda é restringida pelas agências reguladoras e deve atender a certos requisitos específicos na aprovação para este fim ${ }^{[21]}$.

\section{Polímeros Reciclados para Contato com Alimentos}

Materiais como o vidro, aço e alumínio têm sido reciclados para a aplicação em embalagens com uso direto em produtos alimentícios. Fundamentalmente por atuarem como barreira aos contaminantes, impedindo a penetração dos mesmos e também por estarem prontamente limpos nas temperaturas usadas em suas reciclagens $^{[10,11]}$.

O mesmo não ocorre com os materiais poliméricos, pois, devido à sua natureza permeável, podem absorver contaminantes, os quais, se não eliminados adequadamente durante o processo de reciclagem, podem migrar da nova embalagem para o alimento, comprometendo a saúde dos consumidores ${ }^{[22]}$.

A presença de contaminantes, provenientes, principalmente, do mau uso dos consumidores ao reutilizar embalagens plásticas pósconsumo para posterior acondicionamento de produtos químicos, tais como pesticidas, óleos lubrificantes, combustíveis e outros, torna-se provavelmente um dos maiores entraves para a aplicação do polímero reciclado em novas embalagens alimentícias ${ }^{[21]}$.

Estudos divulgados na literatura ${ }^{[15,23-26]}$ com relação à identificação e quantificação das substâncias presentes nas resinas recicladas pós-consumo, mostram que o tipo e concentração das substâncias analisadas dependem de vários fatores, tais como: da fonte da matéria-prima, do processo de reciclagem empregado, das dimensões da amostra analisada e do produto originalmente envasado nas embalagens, além, do tipo de polímero.

Um estudo realizado ${ }^{[23]}$ com poliolefinas pós-consumo indicou a presença de substâncias provenientes de alimentos originalmente envasados nas embalagens, principalmente aquelas utilizadas para conferir odor e fragrância ao alimento, como: limoneno, isopropiléster e ácido palmítico. Ainda, substâncias presentes nas resinas virgens, tais como: hidrocarbonetos alifáticos, alcanos e alcenos também foram identificadas nos materiais reciclados, em concentração similar à encontrada nos polímeros virgens.

Em outro estudo ${ }^{[24]}$, a caracterização de flakes de garrafa PET pós-consumo, revelou, após o processo de lavagem e secagem, a presença de 26 substâncias, com níveis de contaminação entre 10 e $180 \mathrm{mg} \cdot \mathrm{kg}^{-1}$. Ainda, foram identificadas seis substâncias: ácido dodecanóico (1200 mg. $\mathrm{kg}^{-1}$ ), 2-butoxietanol (1000 mg. $\mathrm{kg}^{-1}$ ), limoneno e metilsalicilato (acima de $800 \mathrm{mg} \cdot \mathrm{kg}^{-1}$ ) e 2-metilnaftaleno (215 mg.kg $\left.{ }^{-1}\right)$, com concentração igual ou acima da máxima 
permitida no PET pela FDA, de $215 \mathrm{mg} \cdot \mathrm{kg}^{-1}$, que deriva da concentração na dieta diária máxima de contaminantes admitidos, de $0,5 \mathrm{mg} \cdot \mathrm{kg}^{-1}$ de alimento. Este estudo constatou que o tamanho dos flakes de PET é uma variável importante na quantidade das substâncias extraídas, que aumentam com a diminuição do tamanho do material moído, uma vez que ocorre um aumento da sua área superficial. Assim, o monitoramento dos níveis de contaminação de flakes de PET requer uma análise representativa do material, com relação ao seu tamanho ${ }^{[25]}$.

Os estudos descritos anteriormente reforçam a necessidade da utilização de processos de reciclagem que assegurem a pureza do material de forma a não comprometer a saúde dos consumidores. Entretanto, os contaminantes presentes na resina reciclada podem ser extremamente variados, o que dificulta uma análise qualitativa mais rigorosa sobre sua identificação e toxicidade. Assim, a utilização de polímeros reciclados visando à confecção de embalagens plásticas para contato com alimentos deve atender guias de segurança estabelecidos pelas agências reguladoras que tratam da adequação de materiais para contato com produtos alimentícios. Nos Estados Unidos, este controle é feito pela Food and Drug Administration - FDA ${ }^{[21]}$, na Europa, pela European Food Safety Agency - EFSA ${ }^{[27]}$, e no Brasil pela Agência Nacional de Vigilância Sanitária - ANVISA ${ }^{[28]}$.

Em 1992, a FDA publicou o primeiro guia desenvolvido para assistir empresas interessadas em testar a segurança de seus processos na produção de materiais reciclados aptos a entrarem em contato com produtos alimentícios ${ }^{[21]}$. Desde então, algumas considerações adicionais foram feitas, permitindo a utilização de resinas recicladas, tais como polietileno naftalato (PEN) e PET, via processo químico ${ }^{[21]}$. Já a reciclagem mecânica é permitida desde que o fabricante comprove cientificamente a eficácia do processo na produção de materiais com pureza adequada. Segundo a FDA, isto implica em simular o mau uso dos consumidores, seguindo procedimentos de contaminação padronizados denominados "challenge tests", que consistem na contaminação controlada do polímero virgem usando diferentes tipos de substâncias. Assim, a eficácia do processo de reciclagem não é comprovada pela remoção dos contaminantes "reais" presentes no polímero reciclado, mas sobre a eficiência de limpeza supondo o pior caso de contaminação ${ }^{[21,28,29]}$.

Os contaminantes selecionados pela FDA representam materiais presentes em produtos acessíveis ao consumidor e são divididos em cinco classes: volátil e não-polar; volátil e polar; não-volátil e não-polar; não-volátil e polar e organometálicos. Clorofórmio, tolueno e benzofenona são alguns exemplos de contaminantes. Os dois primeiros podem ser encontrados em solventes de limpeza, representando, respectivamente, as classes: volátil polar e volátil não-polar. A benzofenona representa um pesticida de características não-polar, conhecido como Diazinon. Como exemplo, tem-se um estudo na literatura ${ }^{[30]}$ utilizando a benzofenona como contaminante. Nele foi estudada a migração deste contaminante presente em papel cartão reciclado e a atuação de filmes de PP como barreira funcional.

Após o procedimento de contaminação estabelecido pela FDA, que é feito durante tempo e temperatura pré-estabelecidos, o material é drenado e submetido ao processo de reciclagem em questão. O processo pode ser considerado eficaz se a concentração de cada contaminante, no material reciclado, não exceder uma concentração na dieta diária de $0,5 \mathrm{mg} . \mathrm{kg}^{-1}$ ou de $1,5 \mathrm{mg}$ de alimento/pessoa/ dia na questão da ingestão diária estimada (IDE), considerada pela FDA como de risco negligenciável à saúde do consumidor ${ }^{[21]}$. Tanto os dados da concentração na dieta diária quanto da ingestão diária estimada são obtidos por meio de cálculos, que leva em consideração o fator de consumo e concentração total do contaminante presente em um dado alimento.
A FDA analisa caso a caso, e se o processo de reciclagem sob avaliação não for capaz de promover a remoção dos contaminantes ao nível aceitável, fatores adicionais ou limitações na utilização do material, podem ser utilizados para justificar que o uso da embalagem reciclada não promoverá migração suficiente dos contaminantes para o alimento colocando em risco a saúde do consumidor. Como exemplo, pode-se citar: a utilização de blenda de polímero virgem e polímero reciclado, controle da fonte do material reciclado, uso restrito e utilização de barreira funcionais ${ }^{[21]}$.

$\mathrm{Na}$ questão da fonte dos materiais reciclados os recicladores manifestam interesse, preferencialmente, por resíduos industriais, pelo fato de, normalmente, estes resíduos serem constituídos por um só tipo de resina, por terem constância na qualidade e na quantidade, em relação às outras fontes de captação, e por não apresentarem sujeira ou contaminação ${ }^{[31]}$. No caso das barreiras funcionais, estas podem ser utilizadas para a formação de uma camada protetora entre o alimento e a resina reciclada. Esta camada deve possuir o efeito suficiente de barreira para minimizar a migração de possíveis contaminante presentes no polímero reciclado, abaixo das quantidades que poderiam ser perigosas para a saúde humana ou ainda, que poderiam alterar as características organolépticas dos alimentos. O recobrimento com óxido de silício ${ }^{[32]}$, a deposição com filmes de carbono amorfo ${ }^{[33]}$ e a utilização de uma camada adicional de polímero virgem ${ }^{[34]}$ tem sido explorados como barreiras funcionais para PET reciclado. A deposição de filmes de carbono amorfo em PET reciclado tem se mostrado eficaz na redução da migração de contaminantes orgânicos, especialmente para os de natureza não-volátil, como benzofenona e lindano. Filmes de carbono amorfo com espessura de $120 \mathrm{~nm}$ podem reduzir a migração $\left(40{ }^{\circ} \mathrm{C} / 14\right.$ dias $)$ de benzofenona e de lindano em 97 e $100 \%$, respectivamente, utilizando solução de etanol a $10 \%{ }^{[33]}$. Substâncias de natureza volátil são mais facilmente eliminadas durante o processo de extrusão do material reciclado. Isto foi verificado especificamente para amostras de $\mathrm{PP}^{[35]}$, que passaram por processo de extrusão após a contaminação com clorofórmio e tolueno, seguindo procedimento da FDA.

Ao contrário do que ocorre com o PET, a utilização de outros tipos de polímeros reciclados, ainda tem recebido pouca atenção com relação ao assunto e poucos trabalhos são encontrados na literatura ${ }^{[35,36]}$.

No Brasil, em dezembro de 1998, a publicação da portaria $n^{\circ}$ 987, pela Secretaria de Vigilância Sanitária do Ministério da Saúde, tornou possível à utilização de PET pós-consumo para a confecção de embalagens multicamada (constituída por uma camada interna - barreira funcional - do material virgem) destinadas ao acondicionamento de bebidas carbonatadas não alcoólicas ${ }^{[37]}$

A pressão externa de algumas multinacionais com interesse no mercado brasileiro, o interesse comum do Mercosul e a necessidade de colaborar para a ampliação dos índices de reciclagem tornaram possível uma abertura na legislação brasileira para a aplicação de PET reciclado para contato direto em embalagens de alimentos, ou seja, sem a necessidade da utilização do polímero virgem como barreira interna ${ }^{[38]}$. Em 2008, por meio da resolução RDC $\mathrm{n}^{\circ}$ 20, a ANVISA estabeleceu a possibilidade para produção de PET reciclado para contato direto com alimentos ${ }^{[28]}$. A principal exigência para tal finalidade é o registro do produto na ANVISA, onde o rótulo da embalagem deve conter o nome do produtor, número de lote e a expressão PET-PCR (PET pós-consumo reciclado), além da utilização de tecnologias aprovadas pela FDA ou outra agência reconhecida, que comprovem a limpeza e descontaminação do material reciclado de forma a impedir a migração dos possíveis contaminantes da resina para o alimento. 


\section{Tecnologias}

A adequação do material plástico reciclado visando o acondicionamento de alimentos ou bebidas, seguindo o guia sugerido pela FDA, pode ocorrer por meio da reciclagem mecânica utilizando as tecnologias superclean ${ }^{[39,40]}$, flake-to-resin ${ }^{[41]}$ e bottleto-bottle ${ }^{[40]}$, todas desenvolvidas para a produção de PET reciclado grau alimentício.

O processo superclean consiste em submeter o polímero a uma etapa de lavagem intensa com produtos químicos a temperaturas próximas de $260{ }^{\circ} \mathrm{C}$ sob pressão. Após essa etapa, o material é exposto ao vácuo durante períodos de tempo pré-determinados com posterior filtragem ${ }^{[40]}$.

A tecnologia conhecida como flake-to-resin (FTR), combina a produção de PET virgem e reciclado, descontaminado via superclean, em um único processo. Este é constituído de um reator onde ocorre a esterificação e policondensação para a produção do pré-polímero virgem, que abastece a linha principal do processo. Em uma segunda linha, flakes de PET pós-consumo são parcialmente despolimerizados com etileno glicol até atingir um grau de polimerização semelhante ao do pré-polímero virgem. A última etapa do processo consiste na união das linhas de produção, onde ocorre a mistura do PET pós-consumo (despolimerizado) com o pré-polímero virgem. Esta tecnologia permite o aumento da viscosidade intrínseca, remoção dos contaminantes pós-consumo e dos subprodutos gerados pela polimerização devido à combinação de alto vácuo (aproximadamente $100 \mathrm{~Pa}$ ), temperatura (acima de $270{ }^{\circ} \mathrm{C}$ ) e tempo de residência (mais de 60 minutos). Após a policondensação, a massa polimérica resultante é convertida em pellets, que são diretamente utilizados para a confecção de préformas ${ }^{[41]}$.

A tecnologia bottle-to-bottle ${ }^{[40]}$, corresponde a uma etapa adicional do processo de reciclagem tradicional. O material é separado, lavado, cortado ou moído e depois encaminhado para a extrusão. A etapa adicional corresponde à passagem por um reator de policondensação, onde ocorre o aumento da viscosidade do PET. Durante a policondensação a resina é submetida a uma temperatura de $270{ }^{\circ} \mathrm{C}$ por um período superior a 15 horas em atmosfera inerte ou vácuo. Isto garante a eliminação dos possíveis contaminantes, bem como aumento de massa molar.

Muitos processos desenvolvidos para a utilização de material reciclado para contato com alimento foram patenteados ${ }^{[42-45]}$. Dentre estes encontra-se a patente WO 2008/017843 $3^{[42]}$ que utiliza a lavagem dos flakes de PET com produtos alcalinos e surfactantes para a remoção inicial dos contaminantes. O processamento em extrusora dupla-rosca feito sob vácuo após a lavagem garante a remoção adicional dos mesmos. O processo descrito na patente WO 00/77071 ${ }^{[43]}$ utiliza blenda de PET virgem e reciclado $(25 \%)$ para atender os requisitos da FDA. O material reciclado é limpo em solução alcalina, extrudado e processado com a resina virgem. A blenda final é ainda submetida a um processo de polimerização no estado sólido para a adequação da viscosidade intrínseca do material. A patente PCT/BR05/000117[44] utiliza atmosfera de ar quente e gás inerte, seguido de extrusão, peletização e cristalização para a descontaminação do PET e adequação do material reciclado para contato com alimento.

\section{Mercado}

Nos EUA, a reciclagem de polímeros para contato com alimentos é permitida desde $1990^{[21]}$. Atualmente, este país apresenta-se como um dos que mais reciclam polímeros para esta finalidade, atingindo diversos produtos, como bebidas e embalagens para alimentos perecíveis e não perecíveis, assim como mostrado na Figura $2^{[21]}$.
Até junho de 2010, a FDA autorizou 137 empresas de reciclagem de diversos tipos de polímeros a produzirem embalagens de alimentos ${ }^{[21]}$. $\mathrm{O}$ ascendente uso dos polímeros recicláveis nos Estados Unidos é explicado, dentre outros fatores, pela criação da regulamentação que exige a utilização de até $25 \%$ da resina reciclada na composição total na confecção de embalagens ${ }^{[46]}$. Dentre os polímeros reciclados, o PET é o mais utilizado para a confecção de embalagens alimentícias (Figura 3), o que pode ser explicado pelo grande consumo de bebidas não alcoólicas carbonatadas, que gera grandes quantidades de embalagens de rápido descarte neste país ${ }^{[21]}$.

No Brasil pelo menos dois fornecedores já atuam no mercado oferecendo o sistema de reciclagem bottle-to-bottle para a produção de PET grau alimento, as alemãs OHL Engineering e a Krones ${ }^{[40]}$. A empresa Bahia PET foi a pioneira no desenvolvimento de reciclados para contato com alimentos, por meio do processo bottle-to-bottle,

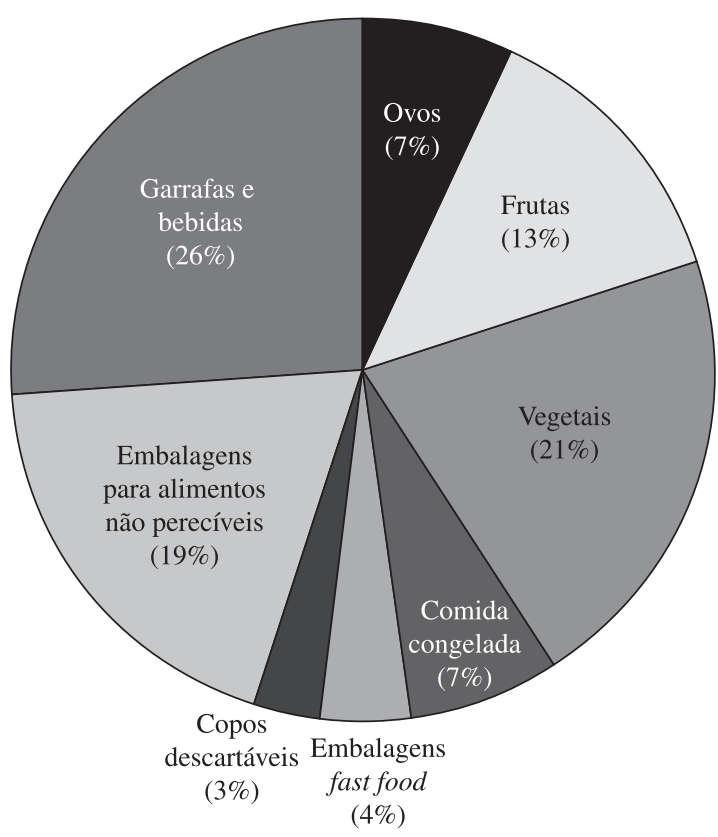

Figura 2. Aplicações de polímeros reciclados para embalagens destinadas a entrar em contato com alimentos ${ }^{[21]}$.

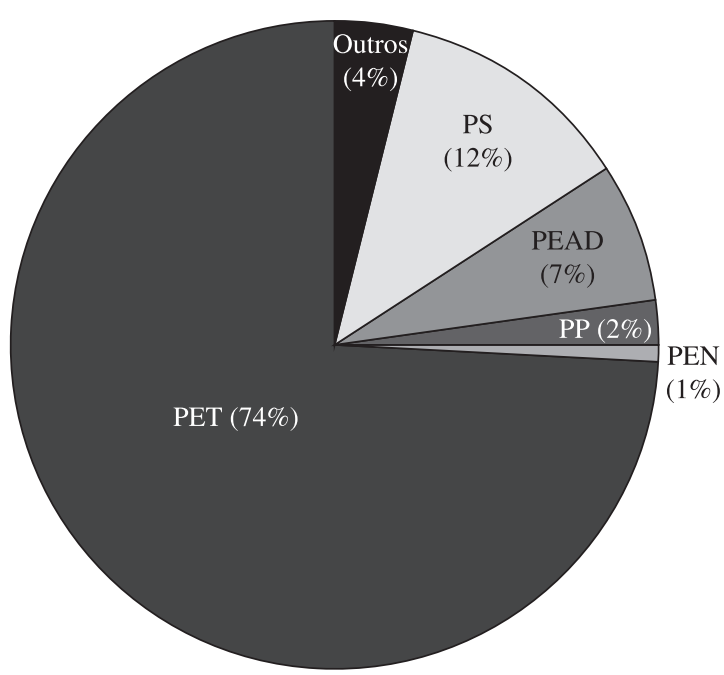

Figura 3. Porcentagem de uso dos polímeros reciclados para contato com $\operatorname{alimentos}^{[21]}$. 
que utiliza tecnologia desenvolvida na Alemanha com aprovação da FDA. Após a liberação da ANVISA para esta empresa, outras recicladoras, como a fluminense CPR e Global PET, entraram com pedido de autorização ${ }^{[40]}$. Porém, devido à lei ser recente, somado com a forte oposição da sociedade no uso de reciclado em contato com o alimento, ainda há uma grande carência de dados e informações a respeito deste mercado no Brasil ${ }^{[47]}$.

\section{Conclusões}

O descarte inadequado de grandes volumes de resíduos, principalmente os de rápido descarte, resulta em um grande problema no gerenciamento dos RSUs no Brasil. Neste cenário, os plásticos ocupam o segundo lugar na composição, contribuindo com $22 \%$ em massa. Dados estatísticos apontaram o setor de embalagens alimentícias como a principal geradora destes resíduos. Assim, a reciclagem destes materiais é sem dúvida a melhor alternativa para minimizar problemas ambientais e aumentar o tempo de vida útil dos aterros sanitários.

Assim, a adequação do material plástico reciclado visando o contato com alimentos pode ocorrer por meio das tecnologias superclean, flake-to-resin e bottle-to-bottle, todas desenvolvidas para a produção de PET reciclado grau alimentício.

Apesar de ser comum no exterior o uso de polímeros reciclados para contato com alimentos, no Brasil, foi homologado pela ANVISA apenas em 2008 para o uso do PET reciclado para esta finalidade, sem a necessidade de utilizar uma barreira funcional.

Analisando os vários polímeros, o PET se destaca como a principal resina reciclada para o mercado de embalagens para contato com alimento. Entretanto, apesar do avanço nesta área, ainda existe uma carência elevada, com relação às pesquisas científicas e dados mercadológicos relacionados ao estudo e aplicação de outros tipos de polímeros reciclados para contato com o alimento.

\section{Agradecimentos}

Os autores agradecem a Universidade Federal do ABC pelo apoio à pesquisa em desenvolvimento.

\section{Referências Bibliográficas}

1. Cruz, S. A.; Farah, M.; Zanin, M. \& Bretas, R. E. S. - Polímeros, 18, p. 144 (2008). http://dx.doi.org/10.1590/S0104-14282008000200012

2. Instituto Brasileiro de Geografia e Estatística - IBGE. - "Pesquisa Nacional de Saneamento Básico" (2008). Disponível em: <http://www. ibge.gov.br/home/estatistica/populacao/condicaodevida/pnsb2008>. Acesso em: jan. 2011.

3. Associação Brasileira de Empresas de Limpeza Pública e Resíduos Especiais - ABRELP. - "Panorama dos resíduos sólidos no Brasil" (2009). Disponível em: <http://www.abrelpe.org.br>. Acesso em: abr. 2010.

4. Companhia de Tecnologia de Saneamento Ambiental - CETESB. - "Inventário Estadual de Resíduos Sólidos Domiciliares" (2008). Disponível em: <http://www.cetesb.sp.gov.br/Solo/publicacoes.asp>. Acesso em: ago. 2010.

5. Calderoni, S. - "Os bilhões perdidos no lixo”, Humanitas Editora, São Paulo (1999).

6. Mancini, S. D. \& Zanin, M. - Plást. Ind., 2, p.118 (2000).

7. Compromisso Empresarial para Reciclagem - CEMPRE. - "Pesquisa Ciclosoft". Disponível em: <http://www.cempre.org.br>. Acesso em: ago. 2010.

8. Pinheiro, J. \& Girard, L. - Estudos Tecnológicos, 5, p. 313 (2009).

9. Pipatti, R.; Sharma, C. \& Yamada, M. - "2006 IPCC Guidelines for National Greenhouse Gas Inventories". Disponível em: <http://www.
ipcc-nggip.iges.or.jp/public/2006gl/pdf/5_Volume5/V5_2_Ch2_ Waste_Data.pdf $>$. Acesso em: ago. 2010.

10. Associação Brasileira de Embalagens - ABRE. "Reciclagem no Brasil". Disponível em: <http://www.abre.org.br>. Acesso em: ago. 2010.

11. DATAMARK Market Intelligence Brazil. Disponível em: <http:// www.datamark.com.br>. Acesso em: ago. 2010.

12. American Society for Testing and Materials - ASTM. - "ASTM D503390”, Filadélfia, p.307 (1991).

13. Ehring, R. J. - "Plastic Recycling: products and processes", Hanser Publishers, New York (1992).

14. Spinacé, M. A. S. \& Paoli, M. A. - Quím. Nova, 28, p.65 (2005).

15. Mancini, S.; Schwartzman, J. A. S.; Nogueira, A. R.; Kagohara, D. A. \& Zanin, M. - J. Clean Prod., 18, p.92 (2010). http://dx.doi.org/10.1016/j. jclepro.2009.09.004

16. Romão,W.; Franco,M. F.; Bueno, M. I. S. \& Paoli, M. A. - Polym. Test., online (2010).

17. Romão, W.; Franco, M. F.; Iglesias, A. H.; Sanvido, G. B.; Maretto, D. A.; Gozzo, F. C.; Poppi, R. J.; Eberlin, M. N. \& Paoli, M. A. - Polym. Degrad. Stabil., 95, p. 666 (2010).

18. Santos, W. N.; Agnelli, J. A. M.; Mumerry, P. \& Wallwork, A. - Polym. Test., 26, p.216 (2007).

19. Santos, A. S. F.; Agnelli, J. A. M.; Trevisan, D. W. \& Marich, S Polym. Degrad. Stabil., 77, p.441 (2002). http://dx.doi.org/10.1016/ S0141-3910(02)00101-5

20. Cruz, S. A. \& Zanin M. - Polym. Degrad. Stabil., 80, p.31 (2003). http://dx.doi.org/10.1016/S0141-3910(02)00379-8

21. U S Food and Drug Administration - FDA. - "Food Ingredients \& Packaging". Disponível em: <http://www.fda.gov>. Acesso em: ago. 2010.

22. Huber, M. \& Franz, R. - Dtsch. Lebensm.-Rundsch., 93, p.328 (1997).

23. Camacho, W. \& Karlsson, S. - Polym. Degrad. Stabil., 71, p.123 (2000). http://dx.doi.org/10.1016/S0141-3910(00)00163-4

24. Konkol, L. M.; Cross, R. F.; Harding, I. H. \& Kosior, E. - Food Addit. Contam., 20, p.859 (2003). http://dx.doi. org/10.1080/0265203031000156088

25. Konkol, L. M.; Cross, R. F.; Harding, I. H. \& Kosior, E. - Food Addit. Contam., 20, p.972 (2003). http://dx.doi.org/10.1080/0265203031000 1606023

26. Franz, R. \& Welle, F. - Food Addit. Contam., 22, p.999 (2005).

27. European Food Safety Agency - EFSA. Disponível em: <http://www. efsa.europa.eu>, Acesso em: ago. 2010.

28. Agência Nacional de Vigilância Sanitária - ANVISA. - "Sistema de vigilância sanitária". Disponível em: < http://www.anvisa.gov.br>. Acesso em: ago. 2010.

29. Romão, W.; Spinacé, M. A. S. \& Paoli, M. A. - Polímeros, 19, p.121 (2009).

30. Song, Y. S.; Begley, T.; Paquette, K. \& Komolprasert, V. - Food Addit. Contam., 20, p. 875 (2003). http://dx.doi.org/10.1080/026520303100 01597592

31. Leite, P. R. - "Revista Tecnologística", Publicare, São Paulo (1999).

32. Welle, F. \& Franz, W. - Food Addit. Contam., 25, p. 788 (2008). http:// dx.doi.org/10.1080/02652030701704755

33. Cruz, S. A.; Zanin, M. \& Nerin, C. - Food Addit. Contam., 23, p.100 (2006). http://dx.doi.org/10.1080/02652030500384064

34. Widén, H.; Leufve, A. \& Nielsen. - Food Addit. Contam., 21, p. 993 (2004).

35. Garcia, P. S. - "Avaliação dos tipos de processamento na descontaminação e na degradação do polipropileno reciclado", Dissertação de Mestrado, Universidade Federal do ABC, Santo André, Brasil (2010). 
36. Coulier, L.; Orbons, H. G. M. \& Rijk, R. - Polym. Degrad. Stabil., 92, p. 2016 (2007). http://dx.doi.org/10.1016/j.polymdegradstab.2007.07.022

37. Regulamento técnico Mercosul: Embalagens descartáveis de Poli(tereftalato de etileno) - PET- multicamada destinadas ao acondicionamento de bebidas não alcoólicas carbonatadas, MERCOSUL/GMC/RES No 25/99.

38. Santos, A. S. F.; Agnelli, J. A. M. \& Manrich, S. - Polímeros, 14, p.307 (2004). http://dx.doi.org/10.1590/S0104-14282004000500006

39. Ohkado, Y.; Kawamura, Y.; Mutusuga, M.; Tamura, H. \& Tanamoto, K. - J. Food Hyg. Soc. Jpn., 46, p.13 (2005). http://dx.doi.org/10.3358/ shokueishi.46.13

40. Zamparolli, D. \& Jorge, C. - Rev. Plást. Mod., 405, p. 33 (2008).

41. Welle, F. - Food Addit. Contam., 25, p. 123 (2008). http://dx.doi. org/10.1080/02652030701474227

42. Kosior, E. Recycling process for polyethylene therephtalate (PET). WO 2008/017843A1 (2008).
43. Nichols, C. S. \& Moore, T.C. Food quality polyester recycling. WO 00/77071A1 (2000).

44. Santos, A. S. F.; Agnelli, J. A. M. \& Manrich, S. Processo de descontaminação de poliéster reciclado e uso do mesmo. PCT/ BR05/000117 (2005).

45. Process for preparing food contact grade polyethylene therephtalate resin from waste PET containers. WO 01/21373A1 (2001).

46. Forlli, F. J. \& Faria, J. A. F. - Polímeros, 12, p.1 (2002). http://dx.doi. org/10.1590/S0104-14282002000400002

47. Cruz, S. A. - "Avaliação das propriedades e caracterização de filmes finos depositados por plasma (PECVD) em embalagens de PET reciclado", Tese de Doutorado, Universidade Federal de São Carlos, São Carlos, Brasil (2005).

Enviado: $18 / 08 / 10$

Reenviado: 02/02/11

Aceito: 01/03/11

DOI: $10.1590 / \mathrm{S} 0104-14282011005000052$ 